\title{
El Valle de los Caídos: la ruina y sus evocaciones
}

\author{
El Valle de los Caídos: the ruin and its evocations
}

\author{
Javier Tébar Hurtado \\ Universidad de Barcelona (España) \\ javiertebar@ub.edu \\ http://orcid.org/0000-0002-3497-7739
}

\begin{abstract}
Resumen
Nuestro propósito es reflexionar sobre el concepto de ruina y las evocaciones que suscita a partir de un espacio memorial como es el Valle de los Caídos, situado a pocos kilómetros de Madrid (España), que generó el pasado año 2019 una fuerte controversia política y social en el país. A partir de cuatro aproximaciones diferenciadas, pero que tienen su nexo de unión en el propio monumento heredado de la dictadura franquista, nos interrogamos sobre la relación entre memoria y espacialidad, así como sobre la configuración de un monumento de exaltación de la victoria de la guerra civil cuyas significaciones en el marco del actual sistema democrático son múltiples y contrapuestas, imposibilitando hacer de él un espacio de reconciliación entre los españoles.
\end{abstract}

\section{Palabras Clave}

Memoria; Espacio; Dictadura Franquista; Presos Políticos; Desapariciones Forzadas; Fosas Comunes.

\begin{abstract}
Our aim is to reflect on the concept of ruin and the evocations it raises from a memorial space such as the Valle de los Caídos, located a few kilometres from Madrid (Spain), which generated last year, in 2019, a strong political and social controversy in the country. Starting from four different approaches, but which have their common grounds in the monument itself inherited from the Francoist dictatorship, we wondered about the relationship between memory and spatiality. As well as about the configuration of a monument of exaltation of the victory in the Civil War whose meanings within the current democratic system are multiple and opposed, making impossible to transform it into a space for reconciliation between the Spaniards.
\end{abstract}

\section{Keywords}

Memory; Space; Francoist Dictatorship; Political Prisoners; Forced Disappearances; Mass Graves. 
«Necesitamos ruinas recientes, cenizas nuevas, frescos despojos, eran precisos el ábside quebrado, el carbón en la viga y la vidriera rota para purificar todos los salmos... Benditas las ruinas porque en ellas están la fe y el odio y la pasión y el entusiasmo y la lucha y el alma de los hombres... España varonil, desvelada, inesperada, tiende sobre la mesa sus planos de ciudades en ruinas y exalta la arquitectura heroica de sus fortalezas minadas...» (Foxá, 1937).

El aristócrata y diplomático de carrera Agustín de Foxá (Madrid, 1906-1959) durante los años republicanos era todavía poco conocido como literato, aunque se relacionaba con alguno de los círculos culturales y participaba en la tertulia madrileña de escritores falangistas. Iniciada la guerra se entregó al bando rebelde interpretándolo como un triunfo propio de Falange, de una revolución que tenía el objetivo de la imposición despótica de la cristiandad y de la justicia social, de la posibilidad de recomponer un mundo que veía víctima del progreso deshumanizado y de la defensa de una idea esencialista de España, medieval y anacrónica (Amat, 2010). Algo que el autor expresaba en el artículo "Arquitectura hermosa de las ruinas" publicado en 1937.

El concepto ruina en la lengua española y en alguna de sus acepciones hace referencia tanto a una acción como a su resultado. Así, las ruinas son los restos, por ejemplo de uno o varios edificios derruidos o caídos o bien derribados, constituyendo un conjunto de materiales, a los que también puede denominárseles escombros cuando se sacan de una demolición. Pero las ruinas también evocan tiempo y espacio, caída o decadencia ruina y destrucción completa de un territorio, una sociedad, un sistema, un imperio. Lo que conduce a preguntarse por las causas que lo han podido provocar, cómo y cuándo.

El propósito de este artículo es reflexionar sobre el concepto de ruina y las evocaciones que suscita. Son restos y rastros faltos de un sentido unívoco. En este caso, la aproximación se hará a partir de un espacio memorial como es el Valle de los Caídos, situado a pocos kilómetros de Madrid (España), que generó el pasado año 2019 una fuerte controversia política y social en el país. A partir de cuatro aproximaciones diferenciadas (memoria y espacialización; trabajo de presos; desapariciones forzadas y fosas comunes; ruinas), pero que tienen su nexo de unión en el propio monumento heredado de la dictadura española, nos interrogamos sobre la configuración de un espacio simbólico de exaltación del Estado franquista y de la aparición de significaciones múltiples y contrapuestas en torno a él.

\section{Memoria y espacialización}

Un año después de finalizada la Guerra Civil, el 1 de abril de 1940 el general Franco decretó la elección de "un lugar retirado donde se levante el templo grandioso de nuestros muertos que, por los siglos, se ruegue por los que cayeron en el camino de Dios y de la Patria". En aquella celebración del "I Día de la Victoria", la continuidad del espíritu de guerra se consagraba a valores de una dictadura en la que su Dios 


\section{El Valle de los Caídos: la ruina y sus evocaciones}

protegía a unos y castigaba a otros, y en una única patria donde no cabían todos los españoles. El emplazamiento escogido para establecer ese "lugar perenne de peregrinación, en que lo grandioso de la naturaleza ponga un digno marco al campo en que reposan los héroes y mártires (...)" dejándolos así insepultos “[y] perpetuar la memoria de los que cayeron en nuestra Gloriosa Cruzada", fue en una finca del valle de Cuelgamuros, propiedad del Marquesado de Muñiz, expropiada por algo más de medio millón de pesetas de la época. Este es un paraje situado al suroeste de la sierra de Guadarrama, dentro del municipio de San Lorenzo de El Escorial, tan sólo a 9 kilómetros del monasterio del mismo nombre.

Un año después, otro decreto completaba aquel proyecto con la decisión del Estado de crear un monumento dedicado de manera exclusiva a los "héroes" y los "mártires" que habían combatido del lado de los insurrectos contra el legítimo régimen democrático republicano nacido apenas 8 años antes, en la primavera de 1931. La prensa diaria de la época nombró como "Valle de los Caídos" aquel espacio designado por Franco para la conmemoración y recuerdo del símbolo de la contienda civil. Sin una idea claramente definida de cómo llevarlo a cabo, se pretendía erigir «el monumento que simbolice, que represente plásticamente las virtudes raciales, como las del heroísmo, el ascetismo, el espíritu aventurero, el afán de conquista, el "quijotismo", que forman el todo que inspira y define lo español como una unidad de esencia sublime y una permanente aspiración hacia lo eterno». A los ojos del dictador el Valle de los Caídos debía adquirir la naturaleza de algo que rebasara lo normal y de dimensiones históricas, debía «ser nada más y nada menos que el Altar de España, de la España heroica, de la España mística, de la España eterna» (Sueiro,1976). En definitiva, el Valle de los Caídos se constituyó en un lugar de memoria oficial que alimentó el discurso legitimador de tradición y orden, combinando al mismo tiempo y de manera peculiar dos culturas: la católica y la fascista (Quintana, 2019), y así sería hasta el año 1975.

Esta relación entre memoria y espacialidad no es ajena a un contexto como el período de entreguerras, cuando proliferaron los ejemplos de conversión de los sitios de violencia y de matanzas en masa en lugares de memoria nacional a partir de decisiones políticas de cada uno de los Estados implicados en guerras y conflictos. En Europa miles de tumbas de los soldados caídos en el frente ocuparon espacios funerarios, haciendo efectiva la idea de que "los que morían juntos, debían ser enterrados también juntos" (Winter, 1998). Así, en 1927 y en dos actos que tuvieron lugar de manera simultánea en Francia y lo que entonces era Alemania tuvieron lugar la inauguración de dos grandiosos monumentos (el osario de Douaumont y el de Hohenstein) para conmemorar Verdún y Tannenberg (Von der Goltz y Robert Gildea, 2009); también se institucionalizó la conmemoración de los ausentes con tumbas sin cuerpos, los cenotafios, como el que había sido inaugurado en Londres en 1920. Entre estas políticas públicas de memoria se incorporaron la elaboración de largas listas con los nombres de los caídos que fueron instaladas en los pueblos y las villas (Laqueur, 1994). Cabe recordar que estas prácticas rituales y símbolos también fueron utilizados en el espacio público por parte de la dictadura franquista, 


\section{Javier Tébar Hurtado}

fijando las listas de los “Caídos por Dios y por España”, de los que a día de hoy quedan restos y rastros visibles (Ledesma \& Rodrigo, 2006; Arco Blanco, 2013).

Esta espacialización de la memoria, tal como ha subrayado Míguez, es una cuestión a tener en cuenta para "pensar en genocidio" el golpe militar fracasado que se produjo en el verano de 1936 en España (2014) y que abrió las puertas a una guerra y una revolución. Tal como Míguez propone, adoptar esta perspectiva permite reflexionar sobre la disociación efectiva que tiene lugar entre las distintas violencias ocurridas en el marco de un mismo proceso violento y su posterior reificación memorial (2018). Existen otros ejemplos comparables, situados en el mismo período de entreguerras, que expresarían una común dificultad de combinar fenómeno genocida y conmemoración gloriosa del pasado; este es el caso de la Guerra Civil finlandesa, en la que la gestión de la memoria realizada por los "blancos" vencedores se refiere exclusivamente a la victoria militar en la contienda y como conmemoración del orgullo nacional, ignorando así la violencia sistemática de las ejecuciones sumarias e internamiento en campos de detención llevada a cabo contra los vencidos (Kekkonen, 2012; Tikka, 2014; Heimo \& Peltonen, 2003). Por el contrario, el memorial dedicado a las víctimas "rojas" en el país finlandés que fue inaugurado en 1970, cincuenta años después de los hechos, constituye la monumentalización de la vergüenza de aquello acontecido.

\section{El reencuentro}

En el caso español, pasados 35 años, y tras una larga y cruel agonía que condujo a un «shock tóxico por peritonitis» en la Ciudad Sanitaria de La Paz, Franco fallecía con 82 años el 20 de noviembre de 1975. Cuando tres días más tarde su cuerpo embalsamado fue trasladado a la Basílica del Valle de los Caídos, el entonces abad mitrado Luis María de Lojendio e Irure -antiguo responsable de la propaganda exterior del régimen durante la Guerra Fría- recitó con voz estentórea "Nuestro hermano ha muerto...." Miembros de la Guardia de Franco cargaron el ataúd. Se retiró la bandera que cubría el féretro. Las cuerdas se movieron con precisión en el foso recubierto de plomo, después de la sorpresa de encontrar a un ex combatiente sexagenario herido que nadie sabía cómo ha caído en el interior de la fosa de la que fue rescatado. La ceremonia finalizó con la colocación de una losa de 1.500 kilos de piedra blanca, de Alpedrete, con una sola inscripción bajo una cruz esquemática: "Francisco Franco" (Izquierdo, 1985). Se trataba de "El último caído" del Valle, tal como pretendiera el director Sáenz de Heredia en el documental inacabado que se ideó coincidiendo con la muerte del dictador (Rueda Laffond, 2013). El régimen dictatorial que había construido el monumento llegaría a su fin después de las elecciones generales del 15 de junio de 1977 y tras aprobar en referéndum la Constitución en diciembre de 1978.

Pasaron décadas para que se cerrara una elipsis. Un día de otoño de 2019 los trabajadores de Patrimonio Nacional de España levantaron una inmensa losa de 


\section{El Valle de los Caídos: la ruina y sus evocaciones}

mármol en la Basílica del Valle de los Caídos, haciendo posible un reencuentro con los restos del dictador. Pero ¿qué había significado mantener un monumento como el Valle de los Caídos en una democracia? y ¿qué hacer ahora con los restos de Franco? Estas son dos cuestiones esenciales de un debate que se había prolongado en el tiempo. Sus precedentes nos remontan a los años de la transición política, haciendo evidente la existencia de una memoria dividida, cuando no confrontada, sobre el monumento ${ }^{1}$. Posteriormente, a principios de los años noventa, el entonces abad del Valle de los Caídos, Ernesto Dolado, se apoyó en el abad de Silos, Clemente Serna, y pusieron en marcha una iniciativa para exhumar a Franco y enterrarlo en el cementerio madrileño de Mingorrubio. Esta opción, sin embargo, fue descartada tanto por el gobierno socialista de Felipe González, por considerarla una operación inoportuna, como por parte de las jerarquías de la Conferencia Episcopal española, que adoptaron una posición de prudencia (Vidal, 2019). De esta forma, se contribuyó a dar persistencia a una anomalía en la memoria colectiva del país.

No ha sido hasta fechas más recientes cuando la cuestión sobre el significado y el futuro del Valle de los Caídos se ha vivido con especial intensidad. Concretamente desde julio de 2018, después de la moción de censura al presidente Mariano Rajoy, la primera producida durante la democracia española, y la posterior investidura de Pedro Sánchez. El nuevo presidente del Gobierno hizo la promesa de trasladar lo antes posible, el mes de agosto de ese mismo año, los restos del dictador a Mingorrubio, situado en el barrio de El Pardo dentro del municipio de Madrid, para depositarlos en la cripta familiar donde estaba enterrada la esposa del dictador, María del Carmen Polo y Martínez-Valdés, y cuyo coste de 11,5 millones de pesetas de la época había sido sufragado por el Ayuntamiento de Madrid en 1969.

La propuesta del nuevo gobierno socialista sobre la retirada de los restos de Francisco Franco y del proyecto de redefinición del recinto del Valle los Caídos, gestionado por un Patronato dependiente de Patrimonio Nacional desde 1982, provocó un bronco y continuado debate político, con un especial protagonismo de los partidos de las derechas. El Partido Popular y Ciudadanos se opusieron al Decreto aprobado por el gobierno el 24 de agosto de 2018, a pesar de que cuando se aprobó en el Congreso de los diputados en mayo de 2017 la retirada de los restos del dictador del Valle de los Caídos, el grupo parlamentario del PP se abstuvo y el de Ciudadanos votó a favor.

La Conferencia Episcopal española mantuvo inicialmente una posición ambigua, y finalmente resolvió no mostrar oposición a la decisión del Consejo de Ministros después de las negociaciones de la vicepresidenta Carmen Calvo con las autoridades vaticanas. La decisión del nuevo gobierno socialista se encontró también con la frontal oposición de la familia Franco, que la obstaculizó mediante una batalla judicial en el intento de que los restos mortales del dictador se depositaran en el panteón familiar situado en la céntrica catedral de La Almudena de Madrid. Al

\footnotetext{
1 Por ejemplo, un programa como "La Clave" dedicaría durante los primeros años de la democracia un debate sobre El Valle de los Caídos. 18/11/1983. Consultado en https://www.youtube.com/watch?v=4c9Ww2F2sVE.
} 
producirse una suspensión cautelar de la exhumación, se imposibilitó la decisión del ejecutivo, tomada tres meses antes, de proceder al traslado de los restos mortales el 28 de abril de 2019.

Un informe de la Delegación de Gobierno en Madrid, hecho público en el mes de septiembre de 2019, fue lo que despejó las dudas sobre este asunto, al desaconsejar el traslado al centro de Madrid para evitar problemas de orden público. Asimismo, posteriormente, el 24 de septiembre de 2019, el Tribunal Supremo aprobó por unanimidad llevar a cabo la decisión del Gobierno de sacar los restos del Valle y trasladarlos al cementerio de El Pardo-Mingorrubio. Aquella decisión había tardado más de un año en llevarse a cabo y se producía en el contexto de la campaña electoral, marcada por la tensión respecto al conflicto político catalán, que tuvo lugar el 10 de noviembre de ese mismo año.

Finalmente, se decidió que la exhumación de los restos embalsamados del dictador se llevará a cabo el 24 de octubre de 2019. En una fría mañana de otoño y en medio de un dispositivo de seguridad de la Guardia Civil y la Policía Nacional, reuniendo alrededor de un centenar de medios nacionales y 58 internacionales que se congregaron para cubrir la noticia del acto, el acto reunió a un reducido grupo de autoridades, al frente del que estaba la ministra de Justicia en funciones, Dolores Delgado, en calidad de Notaria Mayor del Reino durante la exhumación. La familia Franco fue recibida al completo, 22 personas entre nietos y bisnietos, en el Valle de los Caídos por el prior Santiago Cantera Montenegro, militante falangista activo y, hasta su ingreso en la Orden de San Benito en 2002, profesor de la Universidad CEU San Pablo. La ceremonia no dejó de ser una escenificación un tanto grotesca del desacuerdo de la familia con la decisión del gobierno socialista. Se ponía punto y final a quince meses de disputa sobre cuál debía ser el destino de los restos mortales de Franco que, después de ser enterrado entre honores, habían permanecido bajo una losa de mármol durante 44 años.

Mientras tanto, en el interior del templo se producía estruendo de mazas y radiales empleadas por los operarios de Patrimonio Nacional para levantar la lápida de mármol y varias adyacentes, hasta aparecer el fondo del féretro abombado, húmedo y con los laterales desvencijados, por lo que se procedió a envolverlo en una bandera con intención de dignificarlo.

El exterior de la Basílica, los 30 mil metros cuadrados de la explanada del Valle, permanecía vacío. No se escuchaban ni cantos del Cara al Sol, Yo tenía un camarada, tampoco el himno tradicionalista Oriamendi, tal como se había producido en noviembre de 1975 con motivo del entierro de Estado. El vasto espacio, antaño ocupado por coloridas multitudes de falangistas, tradicionalistas, ex cautivos, alféreces provisionales, caballeros legionarios, hermandades de combatientes, caballeros mutilados, viriatos y pides portugueses, guardias de hierro rumanos, ustachi croatas y fascistas italianos, ahora se mostraba en su total desnudez. A pesar de la expectación generada, en esta ocasión solo un grupúsculo de franquistas se había concentrado a las puertas del recinto, ondeando una bandera preconstitucional y exhibiendo una pancarta con la inscripción "Franco Vive". 


\section{El Valle de los Caídos: la ruina y sus evocaciones}

Se cerraba así un episodio que ya era pasado, mediante una operación que supuso el desembolso de 63.000 euros del erario público. Una cruz católica y un helicóptero sobrevolando en el cielo gélido de Madrid pasaban a ser imágenes para la historia.

\section{Trabajo de presos: de Cuelgamuros al Valle de los Caídos}

Desde un principio, el dictador mostró una especial obsesión por la forma de construcción de un elemento que consideraba central dentro de aquel recinto, como era la cruz católica. Este símbolo, que se decidió erigir en lo alto del pico de la Nava, terminaría con un fuste de 108 metros, alcanzando la altura de 150 no concluyendo su construcción hasta septiembre de 1956. Su peso era de 81.720 toneladas métricas, a las que se deberían añadir las 20.000 toneladas métricas que suponen las esculturas de Juan de Ávalos; para un total de 201.720 toneladas. Se emplearon en su construcción más de veinte millones de metros cúbicos de hormigón en masa; cerca de veinticinco millones de metros cúbicos de hormigón armado; cuarenta y cuatro millones quinientos mil metros cúbicos de grava; veinticinco millones de metros cúbicos de arena; unos quince millones de toneladas de cemento; quinientas cuarenta y cinco mil toneladas de hierro redondo; doscientas veintisiete mil toneladas de hierro laminado; cuatro millones doscientos treinta mil metros cúbicos de granito labrado, y tres millones setecientos mil metros cúbicos de mampostería para su revestimiento. Todo ello, sólo en la cruz (Sueiro, 1976). La construcción del recinto supuso de por sí un coste para el Estado, pero también una carga a lo largo de los años en el mantenimiento de un monumento de dimensiones faraónicas. Para hacerlo realidad, se requirió de una movilización masiva de mano de obra durante los años de su construcción, parte de ella protagonizada por los presos políticos y comunes, de uso extraordinariamente barato para el Estado franquista, a la vez que fuente de fortuna para algunas empresas constructoras.

En estos tiempos de mentiras disfrazadas de estridentes revisiones históricas por parte de los sectores de la derecha extrema, se ha escrito que aquellos presos, ya fueran políticos o bien condenados por delitos comunes, trabajaron "voluntariamente" en las obras y que gozaron de buenas condiciones de vida y de trabajo. También se ha dicho que este grupo de cautivos eran una minoría, en comparación con los trabajadores libres empleados en la construcción del Valle de los Caídos. Según las cifras de la Dirección General de Prisiones, el número de presos dedicados a estas tareas estaría entre algo más de 300 y por encima de 500 cada año; pero lo cierto es que la afirmación carece de sentido, por cuanto hoy se desconoce en detalle cuántas personas participaron en aquella obra suntuosa, hasta que en 1950 se suprimieron los destacamentos de presos en el Valle de los Caídos. Unos y otros, presos y personal contratado, realizaron su trabajo en duras condiciones, en particular durante los inviernos debido a las bajas temperaturas, a la vez que las medidas de seguridad en el trabajo más elementales provocaron una alta siniestralidad entre ellos, sin disponer de cifras al respecto. 
Entre 1943 y 1950, a las empresas encargadas de llevar a cabo las obras del monumento, en la carretera que conduce al monasterio y en el propio monasterio se les adjudicaron tres destacamentos penales formados por presos políticos. Pero además, sabemos que la decisión de estos trabajadores no podía ser "libre". Eran presos. Otra cuestión bien distinta era que para algunos de ellos, aquellos que tenían impuestas las condenas menos duras y reunían determinadas condiciones familiares, era la única forma de rebajar la pena que se les había impuesto por los tribunales que los juzgaron. Esto se hizo mediante la actuación del Patronato de Redención de Penas por el Trabajo que se había creado en mayo de 1937, todavía en época de guerra, imponiendo así el "derecho obligación" al trabajo del reo, inspirado en la creación, de los batallones de trabajo de prisioneros de guerra. El proyecto entró en vigor el 1 de enero de 1939, formando parte del sistema penitenciario franquista y dependiente del Ministerio de Justicia (Molinero \& Sala \& Sobrequés, 2003; Gómez Bravo, 2007).

Los reclusos, según las autoridades, no podían constituir "un peso muerto al erario público", por lo que estaban obligados a trabajar jornadas de entre diez y doce horas al día sin descanso. De las 14 pesetas mensuales con que la empresa constructora remuneraba al recluso, aparte de pago de los seguros sociales y los descuentos de su manutención por parte de la administración penitenciaria, el preso recibía en mano del Estado para su uso y disfrute 0,50 pesetas diarias. Una vez acogido a la redención de penas por el trabajo, se le abría una cartilla de ahorro por valor inicial de una peseta, para ingresar los pagos por trabajos extraordinarios y las gratificaciones de Navidad o los donativos de las empresas; eso sí, con una condición: los reclusos podrían hacer ingresos en sus cartillas, pero no retirar dinero (Moreno Garrido, 2010).

Conocemos más o menos con detalle, por otro lado, que en 1945 fue destinada a la construcción del Valle una Compañía de los Batallones Disciplinarios de Soldados Trabajadores Penados (BDSTP), dependiente del Ejército, formada por 150 hombres del BDSTP 95. Estos batallones funcionaban bajo la misma lógica que los prisioneros de guerra, calificados ideológicamente como "desafectos" al Régimen, que funcionaron bajo el mando militar entre 1937 y 1939, momento en el que se crearon los campos de prisioneros. Se crearon al menos 72 campos de concentración en toda España a los que se destinaron "Batallones de trabajadores" (BBTT) formados por prisioneros republicanos, denominados posteriormente "Batallones de Soldados Trabajadores" (BDST) a partir de la primavera de 1940. Los prisioneros estaban pendientes de un destino procesal, pero no estaban condenados penalmente. Por tanto, no formaban parte del sistema de redención de penas por el trabajo diseñado por la dictadura. Estos campos estuvieron en funcionamiento entre 1936 y 1947, cuando cerró el último de ellos en activo, el de Miranda de Ebro (Mendiola \& Beaumont 2006; Rodrigo, 2008; García Funes, 2017).

Las empresas adjudicatarias de las obras fueron Banús, Molán y San Román. Las dos últimas permanecerán en el Valle hasta su finalización, con la incorporación de nuevos contratistas y trabajadores libres. A partir de 1950 Huarte y Cía. S.L. se 


\section{El Valle de los Caídos: la ruina y sus evocaciones}

añadió a este grupo de empresas, en su caso empleando trabajadores libres, posiblemente para la finalización de la cruz levantada. Así, en torno a la construcción del monumento, pero también de otras obras públicas durante la etapa de reconstrucción que se vivió en los años de posguerra, se crearon algunas de las grandes fortunas empresariales españolas. Este es el caso de Banús, propiedad de los hermanos de origen tarraconense José y Juan Banús Masdeu, que años después construirían la lujosa zona turística malagueña de Puerto Banús, en la Costa del Sol, aprovechando el boom económico de los años sesenta. Entre estas empresas constructoras y promotoras inmobiliarias bien conectadas con el poder del llamado "Nuevo Estado" también estuvo Huarte y Cía. S.L., creada por el empresario navarro Félix Huarte Goñi y que hoy es la «H» de la multinacional OHL.

En conclusión, sobre este tema es necesario no jugar a la confusión como hacen aquellos que dicen hacer una revisión crítica y fundamentada de este asunto de la construcción del Valle de los Caídos, cuando lo que hacen es una pura manipulación. Es indudable que aquellos presos políticos llevaron a cabo trabajos asimilables a la figura del trabajo forzoso, según el Convenio número 29 aprobado en 1930 por la Organización Internacional de Trabajo; aunque no cabe descartar que quienes sufrieron la experiencia pudieron vivir y percibir su cautiverio como algo propio del trabajo "esclavo" (García Funes, 2017). Defender hoy que estos trabajadores actuaron como resultado de una elección, es tratar de blanquear un sistema como el de redención de penas franquista y alabar sus resultados. Es una mera exaltación de los supuestos logros de la dictadura, que ni siquiera se sostiene apelando al hecho cierto que el final de aquel sistema de redención no llegó hasta la reforma del Código Penal de 1995, 20 años después de la muerte del dictador. Pero eso ya forma parte de la necesaria reflexión en torno a la propia historia de una democracia consolidada como la española.

\section{De desapariciones forzadas y fosas comunes}

El 23 de agosto de 1957 Franco había creado la Fundación de la Santa Cruz del Valle de los Caídos, con un convenio que otorgaba su gestión a la abadía benedictina, recién construida en roca viva, bajo una cruz colosal, donde se establecía que el monumento tenía como finalidad "rogar a Dios por las almas de los muertos en la Cruzada nacional". El 27 de mayo de 1958 Pío XII dio el visto bueno a la creación de la abadía, y el 16 de julio el abad de Silos Don Isaac María Toríbios tomó posesión, bendijo los locales y celebró al día siguiente la solemnidad de El Triunfo de la Santa Cruz. Así mismo, decidió qué monjes formarían la nueva comunidad y se aprobó el nombramiento de fray Justo Pérez de Urbel, uno de los intelectuales y publicistas del Régimen, procurador en Cortes, entre otros méritos, como su primer abad. La bendición abacial de fray Justo tuvo lugar el 23 de octubre de ese mismo año, dándose el caso insólito de que el acto tuviera lugar en la capilla del Palacio Real de Madrid y que su padrino fuera el mismo jefe del Estado. 
En el preámbulo de decreto que había aprobado la creación de la Fundación se aseguraba que "la fe religiosa de nuestro pueblo (...) el sentido profundamente católico de la Cruzada (...) el signo social del nuevo Estado nacido de la Victoria" eran motivos suficientes para que "la Cruz grandiosa que inspira el Monumento imprime a esta realización un carácter profundamente cristiano (...) Los lustros de paz que han seguido a la victoria han visto el desarrollo de una política guiada por el más elevado sentido de la unidad y hermandad entre los españoles" (Quintana, 2019). Con esta retórica se justificaba que aquel fuera "un lugar de encuentro de los españoles". A partir del verano de 1957, con la creación de la Fundación de la Santa Cruz del Valle de los Caídos, además de depositar en la fosa común del monumento los restos mortales de las víctimas del autodenominado "bando nacional", como se venía haciendo, se decidió trasladar también algunos de los restos de los combatientes republicanos procedentes de otras fosas dispersas en diferentes zonas del país. Sin embargo, no había cesión alguna a la reconciliación entre la sociedad, como se encargó de recordar el propio dictador en su discurso y el abad mitrado Justo Pérez de Urbel al sentenciar, una vez más, que: "La anti-España fue vencida y derrotada". Aunque desde el 1 de agosto de 1958 el recinto pudo ser visitado, no fue hasta el 1 de abril de 1959 -trasladados a la basílica un día antes los restos mortales del fundador de la Falange Española, José Antonio Primo de Rivera- cuando tuvo lugar la inauguración oficial. El acto conmemoraba los veinte años de la finalización de la Guerra de España, ante la presencia de las más altas autoridades del Régimen. Por tanto, más allá de lo material, en lo espiritual el monumento continuaba acogiendo de manera exclusiva a "los héroes y mártires" de la "Cruzada Nacional" tal y como se había proyectado desde un principio.

Paradoja o ironía, fue la dictadura de Franco la que más cadáveres de estas fosas comunes removió como parte del proceso de nutrir de restos mortales la gran cripta del Valle de los Caídos. Miles de ellos fueron exhumados de otras fosas a lo largo de España para ser trasladados al valle de Cuelgamuros. Entre 1959 y 1983 llegaron a su osario 33.847 restos mortales, aunque su número podría ser superior. Es decir, que hoy el Valle de los Caídos alberga una gran fosa común dentro de su recinto, la de mayores dimensiones entre las localizadas en el país.

Aquellas fosas comunes habían sido el resultado del mismo proceso violento con el que arrancó el golpe de Estado fracasado de julio de 1936, cuando los golpistas que se hacían con el control efectivo de un territorio iniciaban una actuación sistemática de eliminación de personas definidas como "contrarias a la Causa Nacional". No obstante, cabría diferenciar los fusilados por causa de los Consejos de Guerra y enterrados en lugares conocidos y registrados, y los fusilados sin juicio ni garantías, dejados en cunetas y otros lugares más o menos desconocidos. De un volumen de asesinados que alcanza y sobrepasa la cifra de 150.000 entre 1936 y 1945 y de una práctica de enterramientos irregulares es de donde surge el fenómeno de las fosas comunes. La desaparición forzada es un delito tipificado por el Derecho Internacional que supone la violación de los Derechos Humanos, que cometida en determinadas circunstancias constituye un crimen de lesa humanidad y, por 


\section{El Valle de los Caídos: la ruina y sus evocaciones}

consiguiente, es imprescriptible desde el punto de vista jurídico. Se tiene constancia que el número de enterramientos en este tipo de fosas puede ascender a una cifra cercana a las 100.000 víctimas, lo que sitúa a España como uno de los países del mundo con mayor número de personas "desaparecidas" (Ferrándiz, 2014; Babiano \& Gómez \& Míguez \& Tébar, 2018).

Lo sucedido en España se vincula con otros fenómenos de violencia masiva, asociados a las violaciones sistémicas de los Derechos Humanos acaecidos durante el siglo XX. En número, este fenómeno sólo es comparable a casos como los de la actual Camboya, donde bajo el terror de los Jemeres Rojos de Pol Pot entre 19751979 se llevaron a cabo matanzas en masa; los de las zonas y bosques de las afueras de Moscú en los que se enterraron las miles de víctimas de las depuraciones estalinistas durante los años treinta; y también las fosas que existen en Ucrania y en determinados territorios del frente oriental, cuando el paso del ejército alemán durante la Segunda Guerra Mundial sembró aquellas tierras con miles de fosas comunes.

En el caso español, muchas de aquellas personas ejecutadas de diversas formas fueron enterradas, en la mayor parte de los casos, sin que sus familias tuvieran noticias exactas de su paradero. Al mismo tiempo, tuvieron lugar también exhumaciones de carácter clandestino llevadas a cabo por los propios familiares, sin disponer de medios para hacerlo. Esto fue así tanto a lo largo del franquismo como durante los años de la etapa de la transición a la democracia en España y aún más tarde (Babiano \& Gómez \& Míguez \& Tébar, 2018).

El estudio efectuado por investigadores y diferentes asociaciones ha permitido constatar la existencia de algo más de 2.000 fosas comunes en el conjunto del territorio español. A fecha de 2011, se habían realizado excavaciones y exhumaciones única y exclusivamente en 332 del total, momento en el que el mapa de fosas dejó de actualizarse, sin que los poderes públicos se implicaran en este proceso. Sólo más recientemente algunas Comunidades Autónomas han impulsado medidas de apoyo para llevarlas a cabo. También ha habido propuestas impulsada desde el Gobierno de coalición de Pedro Sánchez a partir de la presentación de una Propuesta de Ley presentada en enero de 2020, así como la presentada por el grupo de Unidas Podemos en el congreso y en el Senado en abril.

Volviendo al Valle de los Caídos, tras la aprobación de la llamada Ley de la "Memoria Histórica" a finales de 2007, el gobierno socialista de Rodríguez Zapatero mostró una cierta inacción de cara a dar soluciones a la situación patrimonial del monumento y a cómo actuar respecto del osario. Por el contrario, fue la actuación del juez de la Audiencia Nacional Baltasar Garzón la que ofreció una esperanza a las asociaciones de familiares de víctimas al haber dictado un auto judicial el 16 de octubre de 2008 en el que sostenía que durante la Guerra de España y la Dictadura se habían producido graves violaciones de derechos equiparables a la categoría jurídica de crímenes de lesa humanidad, manteniendo que el procedimiento de las desapariciones forzadas fue usado sistemáticamente para entorpecer la identificación de las víctimas e impedir la actuación de la justicia hasta ese momento. 
Esta decisión provocó una gran polémica judicial, política y pública que tuvo mucho que ver con la posterior expulsión de Garzón de la magistratura.

Durante los últimos años, una treintena de familias han iniciado procesos para tratar de recuperar los restos de los suyos de Cuelgamuros y devolverlos a su lugar de origen. Los tribunales han autorizado llevar a cabo la exhumación y traslado a pesar de la oposición mostrada por el prior administrador de la Abadía benedictina, Santiago Cantera. Hace tiempo que algunas de estas familias (la de los hermanos republicanos Manuel y Antonio Ramiro Lapeña Altabás, fusilados en Calatayud en 1936, la de los familiares del soriano Pedro Gil Calonge y del malagueño Juan González Moreno, estos dos últimos agricultores que combatieron en la zona franquista) recibieron la autorización de Patrimonio Nacional, pero han visto dilatarse el proceso ante las cuestiones técnicas o burocráticas que se les plantean desde la Administración.

Ante estas situaciones, cabe concluir que la democracia española dimitió durante los años de la transición política, pero también durante la consolidación de la democracia, de sus funciones y deberes respecto a este asunto. Solo aceptó, tardía y limitadamente, una política de subvenciones para que fuera la sociedad civil organizada la que asumiese un proceso que por su complejidad y su volumen únicamente podría afrontar parcialmente. En esto ha tenido una especial responsabilidad el poder judicial, por cuanto la falta de amparo a las víctimas en sus reclamaciones ha sido proporcional a la falta de implicación de los poderes públicos en la exhumación de los restos.

\section{Sobre ruinas a la deriva}

Hoy el Valle constituye un espacio turístico visitado por miles de personas todos los años. Este hecho justificaría su mantenimiento, puesto que es cierto que su proximidad a la capital madrileña propicia que se oferten habitualmente excursiones y visitas desde la ciudad, de la que les separan 60 kilómetros. "Vive el Valle", como una variante del "Tanatoturismo" o turismo negro o del dolor (Dark tourism), es uno de los reclamos con los que uno puede toparse en las redes sociales, no sin sentir cierta inquietud. La Hospedería Santa Cruz, ubicada en el propio Valle, es un albergue que, según algunas informaciones, recaudaría anualmente un total de 900.000 euros por parte de la comunidad de monjes benedictinos, presentado el recinto a las visitas turísticas como "un grandioso monumento perfectamente integrado en su propio entorno natural". A esto se sumaría el hecho de que la propia comunidad religiosa viene acogiendo la celebración de los actos de afirmación organizados por los nostálgicos del franquismo.

Sin embargo, todas estas razones de su supuesto atractivo ocultan que el monumento construido a lo largo de casi dos décadas y declarado Bien de Interés Cultural por el Estado se presenta como un recinto memorial repleto de significados contradictorios y enfrentados. Lo que esencialmente pretendía en su origen era 
contribuir a la legitimación de la dictadura a través de la elaboración de una identidad nacional. La forma de hacerlo emparenta este monumento con otros espacios ceremoniales y funerarios creados con esta misma funcionalidad que están diseminados tanto por el continente europeo, a partir de la Primera Guerra Mundial, como por otros continentes en los que también se vivieron experiencias de matanzas masivas. Todos fueron construidos con el objetivo de legitimar al Estado que los puso en pie. Muerto el dictador y finalizada la dictadura, no es fuente de ninguna legitimidad al nuevo Estado democrático.

El Valle de los Caídos tiene, sin duda, una gran potencia de evocación simbólica. Expresa un lugar de memoria dividida, no sólo entre los que exaltan la memoria de la Guerra de España en su identificación con los vencedores y aquellos otros que se identifican con los vencidos de aquel conflicto del que han pasado cerca de ochenta años. El monumento evoca y representa en sus diversas caras un anacronismo, expresado de diferentes formas de identificación, tal y como ha planteado Ferrándiz (2011). Entre estas formas diversas se incluye un "anacronismo nostálgico" conectado con los sectores afines al legado político y simbólico del Régimen, muy minoritarios, que releen el monumento desde claves neofranquistas. Este vínculo coexiste con un "anacronismo indiferente" para aquellos que lo ven como un monumento sin un significado político particular, una cuestión magníficamente retratada por la directora y guionista Sandra Ruesga en su corto "Haciendo memoria” (2005) ${ }^{2}$ a partir de una pregunta básica: “¿Cómo es posible que durante tanto tiempo la dictadura franquista no haya significado nada para mí?". Una tercera lectura del monumento se correspondería con el "anacronismo incómodo", tal como expresarían aquellos ciudadanos que ni pueden ni quieren identificarse con el mensaje originario, pero tampoco ven sentido en proponer una resignificación del Valle. Finalmente, los sectores sociales que lo consideran directamente una apología del fascismo y una grave ofensa a los vencidos lo identifican "anacronismo hiriente". El repertorio de sus expresiones es, por tanto, variado pero, al fin y al cabo, sea el que sea el sentimiento que produce el monumento, hoy es un anacronismo (Ferrándiz, 2011). Que esto sea así condiciona cualquier tipo de proyecto sobre su futuro.

El último gobierno de Rodríguez Zapatero encargó un estudio a una Comisión de Expertos que entregó su informe el 29 de noviembre de 2011, acompañado de 33 recomendaciones (2011). Entre éstas estaba la de configurar el monumento como un lugar de memoria para los muertos y las víctimas de la Guerra de España, un centro de interpretación de la dictadura y de la democracia española actual. La idea central sería explicar y no destruir, dar un significado adecuado y no hacer tabula rasa del pasado, además de dignificar el cementerio, trasladar los restos mortales

\footnotetext{
${ }^{2}$ A partir de filmaciones familiares en Super 8, la autora muestra la relación de sus padres con el espacio monumental de El Valle de los Caídos, y, a través de preguntas que va haciéndoles, describe unas actitudes sociales y su variabilidad a lo largo del tiempo, además de la propia relación de ella con el significado de lo que representó la dictadura del general Franco, ver Sandra Ruesga, Haciendo memoria, 2005, https://vimeo.com/37623663
} 


\section{Javier Tébar Hurtado}

del dictador y desplazar los de José Antonio Primo de Rivera, por su condición de víctima de la Guerra, a un lugar sin jerarquía alguna, junto al resto de víctimas enterradas en la cripta de la basílica. Propuestas con las que dijo comprometerse el actual gobierno de España, pero que todavía no se han completado. También se recomendaba establecer un nuevo convenio con la Iglesia española, dado que el antiguo data de 1959, para determinar y distinguir entre la responsabilidad de un lugar de culto como la basílica, inviolable, y las propias de la Administración del Estado.

El Relator Especial de Naciones Unidas, Pablo de Greiff (2014), planteó en 2014 que la destrucción de los símbolos de la dictadura sin discriminación constituiría un error, por cuanto en algunos casos, en particular en el del Valle de los Caídos, lo conveniente sería conservarlo con una orientación vinculada a la lucha antifascista, pasando a ser un lugar de memoria que transmita a las generaciones más jóvenes lo que representó el régimen dictatorial. La finalidad sería que perdiera el carácter divisorio de su memoria y contribuyera a la pedagogía ciudadana y la memoria; algo similar a lo que se llevó a cabo con la antigua Escuela de Mecánica de la Armada, lugar de detención y tortura, en el caso argentino, que en 2004 había pasado a ser en un museo para la memoria y la promoción de los Derechos Humanos.

Transcurrido un lustro, se volvieron a plantear algunas ideas sobre la posible actuación en el Valle de los Caídos: la de convertir en monumento en "El Valle de la Paz" o bien en un centro de interpretación sobre la "Reconciliación", tal como propuso inicialmente el gobierno socialista de Pedro Sánchez durante su primera etapa. Sin embargo, a finales del mes de agosto de 2018 ambas cuestiones fueron descartadas. La última propuesta ha sido planteada por el historiador Fernando Martínez, siendo director de Memoria Histórica del Gobierno socialista anterior, apostando por crear en el Valle de los Caídos un centro de interpretación como se ha hecho en el caso de Auschwitz, en una dirección similar a la sugerida por el Relator Especial de la ONU años atrás. Sin embargo, tal y como se planteó en el Informe de la Comisión de Expertos en 2011, el Valle de los Caídos es todavía un lugar controvertido en la conciencia colectiva de los españoles; y dado que se creó y se perpetúa como un lugar de memoria de la dictadura, lo fundamental es cuestionar y evitar que se mantenga como tal.

El que la memoria sea producto del presente, esté plenamente viva y en disputa, y que su significado sea objeto de constante modificación según el momento político, no parece que haga posible construir otro significado en torno a lo material y simbólico que nos ofrece el Valle de los Caídos: una gigantesca cruz situada sobre una enorme basílica (Juliá, 2011). La propia descomposición de las bases ideológicas que lo sustentan, hace pensar que se transforme paulatinamente en un monumento a la deriva, como lo ha calificado Ferrándiz, tan completamente desanclado de la sociedad española contemporánea como de la eternidad buscada por sus creadores (2011). Ante el irremediable deterioro arquitectónico, el historiador Ricard Vinyes, sostiene que se abre la esperanza de dejar que la naturaleza siga su curso y dé otro significado al monumento, porque la opción, desde su punto de vista, no pasa por la 


\section{El Valle de los Caídos: la ruina y sus evocaciones}

conservación o resignificación del monumento ceremonial "sino por la escuela, que es donde debe ser introducido lo que fue aquel monumento, imperando la exhibición de su hundimiento ético, político, religioso, grandilocuente" (2019).

\section{A modo de conclusión}

Tanto la figura histórica del dictador como el régimen que construyó se han elaborado a partir de mitos y tópicos y de sucesivas capas de mentiras; de falsedades o medias verdades transmitidas en un discurso con un relativo arraigo social. Esto ha comportado la pervivencia de un "pasado que no pasa" (Conan \& Rousso, 1994). A esta situación, se añaden signos de que la Historia en la actualidad ha tocado fondo en la Universidad y que, más pronto que tarde, comenzaremos a escarbar en la "posthistoria", es decir, en el terreno donde no existe la distinción entre la verdad y la mentira, el hecho y la ficción (Arendt, 2006). Todo queda reducido a creencia, a relativismo y validez de lo que son meras opiniones. De esta forma, a los jóvenes, tanto en España como en otros países europeos, las políticas públicas les están "robando la Historia" (Mayayo, 2019).

Entre los estudiantes españoles se sabe que hubo una guerra, que hubo persecución de las personas por sus ideas, que Franco gobernó tres décadas o más, pero cuando en algunas encuestas de las que se disponen se pregunta qué se sabe de Franco los alumnos lo definen como un dictador, pero no de una manera nítida: un $62 \%$ en enseñanza media y un 80,7\% en enseñanza universitaria (Hernández Sánchez, 2016). Estos resultados de las encuestas son sintomáticos sobre un problema general que afecta a la imagen del pasado de la dictadura española, a la propia memoria colectiva del país. Esta es una cuestión que tiene particulares efectos en los niveles educativos de bachillerato (Fuertes, 2018). Ante esta situación, la enseñanza de la Historia Contemporánea más reciente, tal como viene insistiendo Hernández Sánchez, adquiere un carácter de imperativo cívico y democrático, por cuanto en las aulas debería dotarse al alumnado de las claves de los procesos que han conformado la sociedad en que a va insertarse en breve como sujeto en plenitud de derechos políticos, algo que pasaría por darle un protagonismo a esa etapa de la Historia a partir de diseñar un curso propio para su tratamiento, en concreto el último de la secundaria obligatoria (2016). Esto es, por otro lado, algo que se ha producido en otros países de nuestro entorno como Francia o Alemania.

Los discursos de exaltación o de blanqueo del franquismo debilitan la democracia española, difuminan la frontera entre dictadura y democracia. En su peculiar autobiografía del dictador, el escritor Manuel Vázquez Montalbán ya resumía y avanzaba la posible versión dominante sobre el significado de los cuarenta años de dictadura que terminaría imponiéndose en nuestro país durante los años ochenta y noventa del pasado siglo XX.

“Francisco Franco Bahamonde, El Ferrol 1892- Madrid 1975. Militar y político 
español. Destacó en las campañas africanistas de comienzos de siglo y comandó el bando nacionalista durante la guerra civil (1936-1939) frente al bando republicano. Jefe del Estado hasta su muerte en 1975, gobernó con autoridad no exenta de dureza, pero bajo su mando se sentaron las bases del desarrollismo neocapitalista que hizo de España una mediana potencia industrial en el último cuarto del siglo XX" (Montalbán, 1992).

La complejidad del tema nos remite a la conflictiva mirada sobre el pasado a la que alude Jelin cuando afirma que "... Hay una lucha política activa acerca del sentido de lo ocurrido, pero también acerca del sentido de la memoria misma. El espacio de la memoria es entonces un espacio de lucha política,... Es en verdad «memoria contra memoria»" (2017).

El monumento del Valle fue construido con el objetivo de ser un lugar de memoria de los héroes y mártires de una patria defendida por la dictadura, por eso su pervivencia es esencialmente una derrota para una sociedad democrática (Quintana, 2019). No existe posibilidad alguna de que el Valle de los Caídos se configure como un monumento a la reconciliación. La reconciliación la hizo la sociedad española, la Ley de Amnistía del 15 de octubre de 1977 fue el punto de inflexión en el paso de la dictadura a la democracia, después fue cuando se construyó un universo simbólico de "la reconciliación" como ideología de la España democrática (Vinyes, 2014).

Cada país tiene memorias que no son compartidas, sino conflictivas. La capacidad de una democracia se define precisamente, entre otras cuestiones, por saber gestionar la coexistencia de las memorias conflictivas del pasado (Nerín, 2019).

A pesar de la ambigüedad del proyecto original en su pretensión de ser, finalmente el Valle de los Caídos constituiría tanto una fosa común, un lugar de trabajos forzados para presos políticos como un monumento que amenaza ruina. Su anacronismo es evidente, sólo permitiría, por tanto, configurarse como un espacio de conmemoración de la catástrofe que representó el signo de una guerra y sus ruinas, aquellas que reclamaba el falangista Agustín de Foxá en 1937 cuando ensalzaba la guerra civil (Foxá, 1937).

Estas y no otras son la imagen y el relato que se plantea en el terreno de la batalla cultural en curso impulsada desde algunas posiciones de las derechas españolas (Traverso, 2018). Su recuperación del ultranacionalismo adquiere hoy por momentos expresiones combinadas de un neofranquismo exaltado y el rostro de las nuevas derechas i-liberales.

Las aproximaciones que aquí se han ofrecido, con el propio monumento heredado del franquismo como nexo de unión, permiten visibilizar las impunidades perpetuadas a lo largo de la democracia española respecto de los crímenes y vulneraciones cometidos durante la dictadura. A partir de esta actitud se ha contribuido a generar un vacío ético que difícilmente ayuda a consolidar los valores que deberían sustentar el régimen democrático. 


\section{Bibliografía}

Amat, J. (2010). Introducción y selección. En A. de Foxá; Nostalgia, intimidad y aristocracia. Madrid: Fundación Banco de Santander.

Arendt, H. (2006). Los orígenes del totalitarismo. Madrid: Alianza.

Babiano, J. \& Gómez, G. \& Míguez A. \& Tébar, J. (2018). Verdugos impunes. El franquismo y la violación sistémica de los derechos humanos. Barcelona: Pasado \& Presente.

Del Arco, M. A. (2013). Las cruces de los caídos: instrumento nacionalizador en la 'cultura de la victoria'. En C. Fuertes, C. Hernández, J. Marco; No solo miedo. Actitudes populares y dictadura franquista. Granada: Comares.

Conan, E. y Rousso, H.(1994), Vichy, un passé qui ne passe pas. París : Gallimard.

Foxá, A. de (1937), Arquitectura hermosa de las ruinas. Vértice, número 01/04/1937.

Ferrándiz, F. (2014). El pasado bajo tierra. Exhumaciones contemporáneas de la Guerra Civil. Barcelona: Anthropos.

Ferrándiz, F. (2011). Guerras sin fin: guía para descifrar el Valle de los Caídos en la España contemporánea". Política y Sociedad (48:3).

Fuertes, C. (2018). La dictadura franquista en los manuales escolares recientes. Una revisión crítica. Revista Historia Autónoma (12).

García Funes, J.C. (2017). Espacios de castigo y trabajo forzado del sistema concentracionario franquista. (Tesis doctoral), Universidad Pública de Navarra, Pamplona.

Greiff, P. de (2014). Informe del Relator Especial sobre la promoción de la verdad, la justicia, la reparación y las garantías de no repetición. Recuperado de https://digitallibrary.un.org/record/780611?ln=es

Gómez, G. (2007). La redención de penas: la formación del sistema penitenciario franquista, 1936-1950. Madrid: Los Libros de la Catarata.

Heimo, A. \& Peltonen, U-M. (2003): Memories and Histories, Public and Private. After the Finnish Civil War. En K. Hodgkin \& S. Radstone (eds.); Contested pasts: the politics of memory. Nueva York: Routledge.

Hernández Sánchez, F. (2016). El bulldozer negro del general Franco: historia de España en el siglo XX para la primera generación del XXI. Barcelona: Pasado \& Presente.

Informe Comisión de Expertos para el Futuro del. Valle de los Caídos. Entrega al Ministro de la Presidencia. En Madrid, el 29 de noviembre de 2011. Recuperado de https://politicasdelamemoria.org/2011/12/329-informe-de-la-comision-deexpertos-para-el-futuro-del-valle-de-los-caidos / 
Izquierdo, J.Mạ (1985). Una larga y cruel agonía. El País, Madrid, 20/10/1985, Recuperado https://elpais.com/politica/2015/10/28/actualidad/1446061318 427210.html

Jelin, E. (2917). La lucha por el pasado. Cómo construimos la memoria social. Buenos Aires: Siglo XXI Editores.

Juliá, S. (2011). Una imposible resignificación. El País, Tribuna, Madrid, 11/12/2011 Recuperado de https://elpais.com/diario/2011/12/11/opinion/1323558005_850215.html]

Kekkonen, J. (2012). Judicial repression during and after the Finnish (1918) and Spanish (1936-1939) civil wars: A comparative analysis". E M. de Koster \& H. Leuwers \& D. Luyten \& X. Rousseaux (eds.); Justice in Wartime and Revolutions: Europe, 1795-1950. Brussels: Algemeen Rijksarchief.

Laqueur, T.W. (1994). Memory and Naming in the Great War". En J.R. Gillis (ed.) ; Commemorations. The Politics of National Identity. Princeton: Princeton University Press.

Ledesma, J.L. \& Rodrigo, J. (2006). Caídos por España, mártires de la libertad. Víctimas y conmemoración de la Guerra Civil en la España posbélica (1939-2006)". Ayer (63).

Mayayo, A. (2019). Sense futur no hi ha passat. L'Avenç (456).

Mendiola, F. \& Beaumont, E. (2006). Esclavos del franquismo en el Pirineo. La carretera Igal-Vidángoz-Roncal (1939-1941). Tafalla: Txalaparta.

Míguez, A. (2014). La genealogía genocida del franquismo. Violencia, memoria e impunidad. Madrid: Abada.

Míguez, A. (2018). Pensar en genocidio el golpe de 1936, la guerra civil, el franquismo y la transición. Revista Universitaria de Historia Militar (13).

Moreno Garrido, B. (2010). El Valle de los Caídos: una nueva aproximación. Revista de Historia Actual (8:8).

Nerín, G. "Enzo Traverso: "Un món sin utopies és un molt trist"”, El nacional, Barcelona, 11/09/2019. Recuperado de 23/06/2919https://www.elnacional.cat/ca/cultura/enzo-traverso-postfeixismemelancolia-esquerra_395734_102.html

Quintana Trías, Ll. (2019). El fracàs del Valle de los Caídos". L’Avenç (454).

Rodrigo, J. (2008). Hasta la raíz: violencia durante la guerra civil y la dictadura franquista. Madrid: Alianza Editorial.

Rueda Laffond, J.C. (2013). Entre Franco y Juan Carlos. Representación y memoria en televisión y otros medios populares (1966-1975). HAO, (32). 
Sueiro, D. (1976). La verdadera historia del Valle de los Caídos. Madrid: Sedmay Ediciones, 1976.

Tikka, M. (2014). Warfare and Terror in 1918". En T. Tepora \& A. Roselius (eds.); The Finnish Civil War 1918. History, Memory, Legacy. Leiden: Brill.

Traverso, E. (2018). Las nuevas caras de la derecha. Conversaciones con Régis Meyran. Buenos Aires: Siglo XXI Editora Iberoamericana

Vázquez Montalbán, M. (1992). Autobiografía del general Franco. Barcelona: Planeta.

Vidal, J.M. (2019). Un abad del Valle de los Caídos intentó sacar a Franco de Cuelgamuros en los años 90, Eldiario.es 04/11/2019. Recuperado de https://www.eldiario.es/sociedad/abades-intentaron-Franco-ValleCaidos_0_959954418.html]

Vinyes, R. (2014). La buena memoria. El universo simbólico de la reconciliación en la España democrática. Relatos y símbolos en el texto urbano. Ayer (96/4).

Vinyes, R. (2019). Apología de la ruina. Diario Público 11/12/2019. Recuperado de https://blogs.publico.es/otrasmiradas/26551/apologia-de-la-ruina/

Von der Goltz, A. \& Gildea, R. (2009). "Flawed Saviours: the Myths of Hindenburg and Pétain”. European History Quarterly. (39:3).

Winter, J. (1998). Sites of Memory, Sites of Mourning: The Great War in European Cultural History. Cambridge, Cambridge University Press.

Recibido: 02/06/2020

Evaluado: 20/07/2020

Versión Final: 30/08/2020 